\title{
Participation, performance, and outcomes in an undergraduate physics degree: Perspectives on gender and socioeconomic factors
}

\author{
Rachel E. Harrington, Job H. J. Thijssen $\odot$, and Judy Hardy \\ SUPA School of Physics and Astronomy, The University of Edinburgh, \\ James Clerk Maxwell Building, Peter Guthrie Tait Road, Edinburgh EH9 3FD, United Kingdom
}

(Received 12 February 2021; accepted 5 January 2022; published 23 February 2022)

\begin{abstract}
The academic performance of undergraduate physics students at a research-intensive UK university were studied to identify whether there were any significant differences between underrepresented and overrepresented groups. Exit qualification, degree classification, average yearly marks, and course marks were analyzed to determine statistically significant associations with gender or widening participation status. Significant association was found between gender and the integrated masters qualification, with a higher proportion of female students attaining a first class or second class (upper) classification. A performance gap was identified between widening participation and non-widening participation students in second year, but no significant association was found between widening participation status and exit qualification or degree classification. In examining the intersection of gender and widening participation status, no significant association was found between these groups and exit qualification. These results contrast with previous studies, which suggest that the effects of underrepresentation adversely impact academic performance. The reasons why this might be the case, with particular consideration of the context of the sample studied, are discussed.
\end{abstract}

DOI: 10.1103/PhysRevPhysEducRes.18.010114

\section{INTRODUCTION}

There is widespread recognition that underrepresented, or marginalized, groups face barriers that can impact their participation, retention, and achievement in university science, technology, engineering, and mathematics (STEM) education [1,2]. For example, there have been calls for a coordinated national effort in the USA to increase the proportion of underrepresented groups in STEM subjects $[3,4]$, and there are longstanding concerns over the number of women studying science and entering into the scientific workplace $[5,6]$. In the UK, underrepresentation of women and young carers, young people with care experience and individuals with a low socioeconomic status (collectively termed widening participation (WP) students) in university physics is well recognized. Underrepresentation has been shown to have adverse effects on individuals within underrepresented groups, altering self-concept [7] and provoking feelings of selfdoubt and intellectual phoniness [8]. These effects perpetuate a lack of participation in higher education and, for those students who do attend, their academic performance

Published by the American Physical Society under the terms of the Creative Commons Attribution 4.0 International license. Further distribution of this work must maintain attribution to the author(s) and the published article's title, journal citation, and DOI. is often impacted, resulting in performance gaps between underrepresented and overrepresented groups $[9,10]$.

Measurements of academic performance are therefore often used to quantify the impact of underrepresentation. Attainment metrics such as dropout, degree completion, and degree classification are the most commonly used across gender and widening participation studies $[9,11]$. Instruments designed to test students' understanding of specific physics concepts, and how their understanding differs pre- and postinstruction [12], have also been used to look at gender performance gaps in introductory physics courses [10,13-16].

However, underrepresented groups are often considered in isolation, thus omitting the intersectional identities of many students. Furthermore, there has been relatively little research into how performance gaps change throughout the course of a degree program, and therefore to what extent higher education is mitigating or exacerbating the effects of underrepresentation. In gaining understanding as to where interventions are most needed, institutions should be better placed to support students to succeed, and ultimately to reduce the magnitude of underrepresentation by making higher education a more inclusive and welcoming environment.

In this study we investigated the academic performance of undergraduate students in the physics department of a research-intensive UK university to identify whether there were any significant differences between the performance of underrepresented and overrepresented groups. The study 
focused on two underrepresented groups in UK HE: widening participation and women physics students.

\section{BACKGROUND}

Higher education (HE) participation in the UK has expanded dramatically over recent decades, increasing by 1.3 million between 1960 and 2018 [17,18]. Despite this, the enrolment of female and WP students (See Sec. VI for definitions) into higher education physics has not followed the same trajectory. In 1994, female students constituted $50 \%$ of all UK undergraduates, but only $18 \%$ of physics undergraduates [19]. By 2018, 56\% of all UK undergraduates were female, compared to $24 \%$ of physics undergraduates [18].

The picture elsewhere is similar. In the USA, $21 \%$ of students awarded a bachelor's physics degree in 2018 were female, an increase of only $1 \mathrm{pp}$ (percentage point) since 2008 [5]. In comparison, 57\% of all US students awarded a bachelor's degree in 2018 were female, a percentage that has not changed over the previous decade [5]. Across the EU, 20\% of students studying for a bachelor's physics degree in 2018 were female [20]; again, a percentage that has remained essentially static over the previous 5 years.

The $6 \mathrm{pp}$ increase of UK female physics undergraduates over this 24 year period corresponds to an increase of 2332 students $[18,19]$. Considering those UK HE institutions that offer a physics degree [21], on average this corresponds to an increase 51 female students per university, or 2 additional female students per year. Furthermore, given that the proportional increase of female physics undergraduates is the same as for the overall undergraduate population, it would suggest efforts thus far to specifically combat gender imbalances in higher education physics have not been successful.

HE participation has been rising for those from deprived backgrounds, although to a lesser extent in researchintensive institutions, with those from the highest socioeconomic quintile group still 7 times more likely to go to a selective institution in the UK than those from the lowest socioeconomic quintile group [22]. It is difficult to obtain comparative data on the proportion of students who are from WP backgrounds. In the UK, each nation (and, to some extent, each higher education institution) uses a slightly different definition of WP [23] and internationally the situation is similar. One proxy measure is parental qualification; surveys of Institute of Physics members (mainly physics students and graduates in the UK and Ireland) showed that in $2019,7 \%$ of respondents' parents had no qualifications, compared to $11 \%$ in 2015 [25].

The lack of HE participation from underrepresented individuals remains an area of concern. It has driven the growth of research focused on understanding the adverse effects of underrepresentation, and what that means for students who do attend university. Because of the embedded culture of underrepresentation in physics, negative stereotypes have (inadvertently) been attributed to individuals from underrepresented groups. This may result in stereotype threat in these individuals-a fear of confirming a negative stereotype about oneself when completing a task - that can lead to underperformance and lack of confidence [26]. Underrepresented individuals are also susceptible to imposter syndrome, or persistent thoughts of intellectual phoniness, that may even cause people to leave academia through fear of incompetence [27]. Studies have found that the higher education environment influences the extent to which these effects impact an individual and their self-concept (the beliefs they hold about themselves). Recognition by peers and instructors [28], having relevant role models in academic staff [29] and discussing underrepresentation [30] have all been found to strengthen an underrepresented individual's physics identity.

The effects of underrepresentation permeate various aspects of a student's higher education experience and can adversely impact academic performance. Studies have shown that higher dropout rates and lower degree classifications are associated with low socioeconomic status (SES) [31,32]. This difference in academic performance has been partly explained by lower SES individuals bringing less human capital (experience, skills, and quality of education) to university [9]. Interestingly, when prior attainment is accounted for by comparing students with the same grades on entry, those from lower SES are less likely to drop out, more likely to complete their degree and obtain higher degree classifications [9,31,33]. Relatively little research has been conducted looking beyond overall attainment levels for WP students into their academic performance and experiences throughout higher education.

Gender gaps have been identified in university students' understanding of physics concepts. A 2013 study using the Force Concept Inventory (FCI) [12] to compare gender differences in conceptual understanding of Newtonian mechanics before and after instruction across three UK universities [14] found that male students significantly outperformed their female peers both pre- and postinstruction, with the gap narrowing but not disappearing after instruction. A study conducted at another UK university found that significant gender gaps remain even after a threemonth absence of mechanics-related teaching [34]. Interestingly, in both of these studies, when comparing the students' end of course examination results, no statistically significant gender gaps were found. This finding has been replicated in a study of U.S. college students $[10,13]$. More recently, researchers examining gender gaps across various conceptual inventory studies found that very little of the gender gap could be explained by differences in academic performance, but that a substantial part of the gap could be explained by prior physics preparation, measured by pretest scores on the inventories [35]. A similar picture 
emerges when considering degree classification; between 2004-2005 and 2009-2010, 87\% of men and 88\% of women graduating from a UK university with an integrated masters degree in physics gained a first class or upper second class classification (see Sec. IV for an explanation of UK degree classifications), compared to $48 \%$ of men and $59 \%$ of women who graduated with an honors bachelor's degree [11].

Recent studies have highlighted the complexity of this area and the need to take a more nuanced view of perceived gender gaps. For example, a 2016 study critiqued the (presumably unintended) "deficit model" of female underperformance in concept inventories and the underlying assumption that standards are set by male performance [36]. Another study found evidence that, in the U.S., subjects of physics education research (PER) may not be representative of the broader population of physics students, as PER tends to be focussed in larger researchintensive universities [37]. The same study also highlighted the importance of the local context; that it should not be assumed findings from research undertaken in one context will transfer to others [37].

\section{TERMINOLOGY}

The following outlines how the terms widening participation and gender were defined in this study and how students were categorized based on these definitions [38].

Widening participation: An umbrella term used in UK education policy when referring to interventions aimed at increasing participation in $\mathrm{HE}$ from underrepresented groups [39]. A student is classified as widening participation if they fall into one or more of the following categories: attending a school where relatively few students go on to $\mathrm{HE}$, living in low participation neighborhoods, mature students from the aforementioned groups, young carers, young people with care experience, stemming from a low socioeconomic group. Students' WP status as used in this study was determined by the university when the student applied, using contextual indicators [41]. A WP status can only be applied consistently to UK domiciled students; therefore, the non-UK cohort were omitted when comparisons were made between WP and non-widening participating (non-WP) students.

Gender: A perceived identity that may or may not align with biological sex, and may or may not change over time [36]. In this study students were categorized as male or female; two of many possible gender identities. In applying to and entering the university, self-disclosed information such as gender was collected from students. The options available to students when asked to disclose gender were male, female or neither [42]. Because of the small number of students self-disclosing as neither, only comparisons between male and female students were made. In comparison of the two, the terms "gender
TABLE I. Scottish undergraduate qualifications, including commonly used award titles for physics degrees.

\begin{tabular}{lcc}
\hline \hline Qualification & Award title & Years of study \\
\hline Certificate of higher education & CertHE & 1 \\
Diploma of higher education & DipHE & 2 \\
Bachelor's & BSc (Ord) & 3 \\
Bachelor's with honors & BSc (Hons) & 4 \\
Integrated master's & MPhys (Hons) & 5 \\
\hline \hline
\end{tabular}

${ }^{\mathrm{a}}$ Note that Scottish undergraduate degrees take a year longer to complete than elsewhere in the UK.

differences" or "gender gaps" are used as opposed to "sex differences" [36].

\section{CONTEXT}

\section{A. Undergraduate degrees in Scottish higher education}

A summary of undergraduate qualifications awarded by Scottish universities is shown in Table I.

Key features of these degrees include the following:

- Bachelor's degree: Bachelor's degrees may be awarded with or without honors. Bachelor's without honors are also known as ordinary degrees. They are often used as an "exit award" for students who have not met the requirements needed to progress to the 4th year of an honor's degree.

- Integrated master's degree: Integrated master's degrees are honor's degrees that include an additional year of in-depth study at master's level compared to bachelor's honor's degrees. They are common in STEM subjects across the UK.

- Classification of degrees: Honor's degrees are awarded with a classification based on the student's overall academic performance (see Table II). Other undergraduate qualifications, including ordinary degrees, are not classified.

\section{B. Institutional context}

The School of Physics and Astronomy at the University of Edinburgh has an annual undergraduate intake of approximately 150 students, with a gender ratio of 75:25 male to female students and a WP status ratio of $75: 25$ non-WP to WP students. The intake is typically composed of $40 \%$ Scottish students, $30 \%$ from the rest of the UK, and $30 \%$ EU or international students.

TABLE II. Classification of honor's degrees.

\begin{tabular}{lc}
\hline \hline Class & Overall performance \\
\hline First (1st) & $\geq 70 \%$ \\
Upper second $(2: 1)$ & $60 \%-69 \%$ \\
Lower second $(2: 2)$ & $50 \%-59 \%$ \\
Third (3rd) & $40 \%-49 \%$ \\
\hline \hline
\end{tabular}


Students arrive with a range of entry qualifications. Scottish school leaving qualifications (SQA qualifications) are different to those in the rest of the UK. Scottish students have SQA advanced highers (or, more rarely, SQA highers, if they did not go on to take advanced highers), while students from the rest of the UK have A levels. EU or international students have other qualifications such as the International Baccalaureate.

There are two entry points to the undergraduate physics degree at Edinburgh. Students may start their degree in either the first year of the program (known as "first year entry") or directly into second year (known as "direct entry"), depending on their entry qualifications. The entry requirements for direct entry to second year are higher than those for first year entry. Entry requirements for WP students are slightly lower than the standard requirements, in recognition of the challenges that these students may have faced in their school studies.

At Edinburgh, as at other Scottish universities, students normally study a range of subjects in the first two years of their degree (the "pre-honor's" years). This may include taking optional courses (electives) from outwith their chosen specialism. In years three, four and five (the "honor's" years), students focus on their degree specialism. Because of this clear distinction between pre-honor's and honor's, only the results from honor's years are counted towards students' degree classification. At Edinburgh, BSc (Hons) degree classification is determined using a weighted average of results from years three and four in a 50:50 ratio; for the MPhys (Hons) degree, years three, four, and five are used in a 20:40:40 ratio. Years four and five have a higher weighting than year three for MPhys (Hons) because students' performance in their final two years is considered more representative of their performance at graduation.

Optional courses are available to the majority of University of Edinburgh students and nonphysics students can elect to take introductory physics courses. As a result, class sizes are often larger in years one and two, at around 200-300 students [43]. Third year is highly structured, whereas fourth and fifth year contain few compulsory courses, with students able to tailor their studies based on personal interests. For a more in-depth descriptions of the specific requirements of physics degrees at Edinburgh, see Ref. [44].

\section{RESEARCH QUESTIONS AND HYPOTHESES}

This study followed three undergraduate cohorts at the School of Physics and Astronomy at the University of Edinburgh in the UK. It aimed to answer the following research questions:

Looking separately at gender and WP status,

1. Is there a significant association between gender or WP status and educational outcome, either in qualification type or classification obtained?
2. Does a significant performance gap persist through all years of academic study, appear or disappear at a specific point during higher education instruction or not appear at all?

3. Does the nature of a performance gap change when looking specifically at mathematics or physics based courses?

Looking at both gender and WP status,

4. Is there a significant (intersectional) association between gender and WP status, and the qualification type obtained?

To investigate these research questions, the following null hypotheses were used when conducting statistical tests:

$\mathrm{H} 0(1)$ : There is no significant association between gender or WP status and educational outcome, either in the qualification type or classification obtained.

$\mathrm{HO}(2)$ : There is no significant performance gap that persists through all years of academic study.

HO(3): There is no change in the nature of a performance gap when looking specifically at mathematics or physics based courses.

HO(4): There is no significant (intersectional) association between gender and WP status, and the qualification type obtained.

\section{METHOD}

\section{A. Datasets and statistical tests}

Three undergraduate entry cohorts of students were examined in this study, from entry sessions 2012-13, 2013-14, and 2014-15. The dataset is based on 444 students, which includes 114 female students and 112 WP students. Further details, including the gender split and WP numbers for entry sessions 2012-13, 2013-14, and 2014-15 are given in Tables III and IV (see Sec. VII).

Datasets, in the form of Excel spreadsheets, included gender, WP status (for UK domiciled students), individual

TABLE III. Gender split of 2012-13 through 2014-15 cohorts.

\begin{tabular}{lcccc}
\hline \hline & $2012-13$ & $2013-14$ & $2014-15$ & Total \\
\hline Male & $105(85 \%)$ & $121(71 \%)$ & $104(69 \%)$ & $330(74 \%)$ \\
Female & $18(15 \%)$ & $50(29 \%)$ & $46(31 \%)$ & $114(26 \%)$ \\
Total & 123 & 171 & 150 & 444 \\
\hline \hline
\end{tabular}

TABLE IV. WP students, including gender split, of 2012-13 through 2014-15 cohorts.

\begin{tabular}{lcccc}
\hline \hline & $2012-13$ & $2013-14$ & $2014-15$ & Total \\
\hline Male WP & $25(93 \%)$ & $32(78 \%)$ & $29(66 \%)$ & $86(77 \%)$ \\
Female WP & $2(7 \%)$ & $9(22 \%)$ & $15(34 \%)$ & $26(23 \%)$ \\
Total WP & 27 & 41 & 44 & 112 \\
\hline \hline
\end{tabular}


course marks (for compulsory courses), yearly average marks, and exit qualification and classification. Because of the flexibility of academic years four and five, marks from these years were not considered separately in this study. Entries in the dataset marked "No Qualification" refer to students who left the University before completing year 1, or who switched to a different degree program outside of the school. From the data it was not possible to know which of these applied. Although the proportion of female students in the 2012-13 cohort was smaller than in the 2013-14 and 2014-15 cohorts, no significant differences were found between the overall academic performance for the three cohorts. The data were therefore aggregated in order to maximize the sample size.

For privacy reasons, only the tabular data for replotting the figures in this publication are available on the Edinburgh DataShare repository [45].

\section{Research question 1}

As this research question is concerned with students' outcomes on exit, rather than year-on-year performance during their degree (which is addressed in research questions 2-4), first year entry and direct entry students were considered together. Chi-squared tests $\left(\chi^{2}\right.$ tests $)$ were performed to establish whether there was an association between gender or WP status on educational outcome, both in the qualification type and classification obtained. Expected values were calculated manually and the chisquared value was calculated using the CHISQ.TEST function in Excel [46].

\section{Research question 2}

In order to conduct longitudinal analysis, the dataset was cleaned to ensure all students had completed the same courses in the same years. This inevitably led to several students being omitted. The most common reasons for removal were that the student had resat an academic year, taken a year out, completed a year abroad or switched degree program. The courses chosen for analysis were the compulsory courses of the standard physics degree for academic years 1-3 (see the Appendix, Tables V and VI). First year entry and direct entry students take different compulsory courses, so these groups of students were kept separate. After the dataset had been cleaned, no female students remained in the first-year entry cohort of 2012-13, so this entry session does not appear in the aggregated dataset for gender comparisons. For the direct entry gender analysis, and for both first year and direct entry analysis of WP status, all three academic sessions were used.

Two-sample $t$ tests were used to establish whether there was a significant mean difference in yearly averages between the groups of interest. Each two-sample $t$ test was conducted using the T.TEST function in Excel [46] and assuming equal variance. Equal variance was assumed after comparison of the standard deviations and box plots of the relevant data had been made.

Paired $t$ tests [46] were also conducted to establish whether the yearly academic performance for male, female, WP, or non-WP students significantly changed. These tests ensured that significant changes in a category's performance were identified, irrespective of whether it was significant in comparison to another group, thereby considering each category its own right. In taking this approach we were mindful that previous research has tended to only directly compare female to male students, and WP to nonWP students. This has attracted criticism for assuming an implicit "deficit model," i.e., a standard to which other groups should be compared [36].

\section{Research question 3}

The compulsory courses in academic years 1 and 2 were separated into mathematics and physics courses. The analysis was only conducted on first year entry students. The dataset used for this analysis also excludes students on some specialized degrees (mathematical physics and theoretical physics) who took a different set of compulsory courses. Two-sample $t$ tests were used to establish whether the type of course affects how underrepresented groups perform academically.

\section{Research question 4}

$\chi^{2}$ tests were conducted to explore the possible association between gender and WP status, using particular combinations of exit qualifications to form the testing cohorts. As stated in Sec. III, a WP status can only be consistently applied to UK domiciled students. The intersectionality cohort therefore also only contains UK domiciled students. Because of the difference in domicile between the gender dataset and widening participation dataset, comparisons should not be made between the results obtained when they are considered separately, but should be confined to the intersectionality section.

For all four research questions, statistical tests were conducted with a 0.05 significance level. All tests used were parametric and therefore assumed a normal distribution. This assumption was checked by plotting histograms (using Sturges' rule for number of bins) and checking the skewness and kurtosis of the relevant data.

\section{RESULTS AND DISCUSSION}

\section{A. Gender}

The gender split of students entering the School of Physics and Astronomy in 2012-13, 2013-14, and 201415 is shown in Table III. The percentage of each cohort that were female is $15 \%, 29 \%$, and $31 \%$, an average of $26 \%$. This is consistent with female physics enrollment across UK HE, which on average is $23 \%$ [18]. 


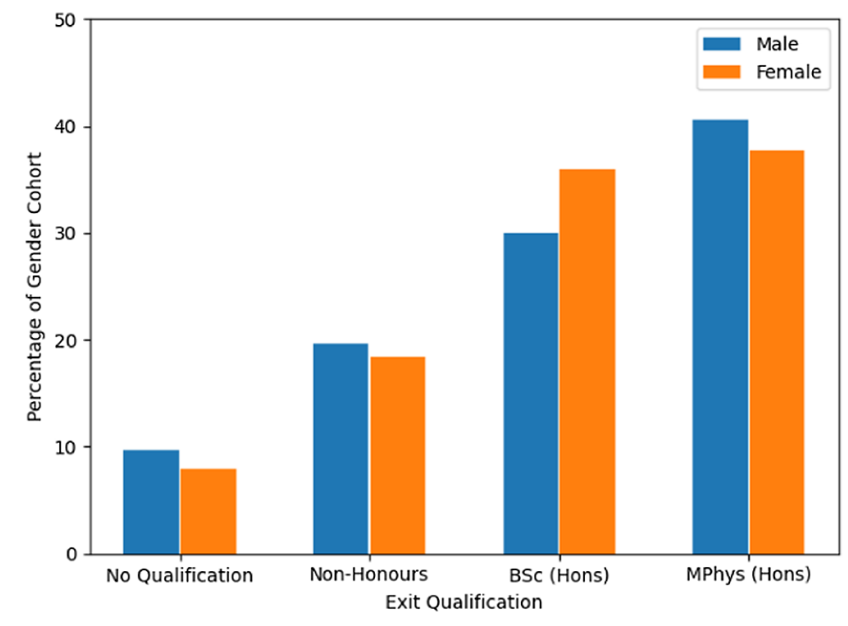

FIG. 1. Percentage of cohort exiting with each qualification type, disaggregated by gender $(N=444, \quad$ Male $=330$, Female = 114). CertHE, DipHE, and BSc (Ord) have all been grouped as "non-honor's" due to low numbers.

\section{Exit qualification and classification}

The percentage of male and female students that attained each type of exit qualification for the aggregated dataset is shown in Fig. 1. From a qualitative inspection of the figure, it can be seen that the outcomes for both genders follow a similar distribution. A $\chi^{2}$ test confirmed that there is no statistically significant association between gender and exit qualification.

The largest gender difference is for the BSc (Hons), where $6 \mathrm{pp}$ more female than male students exited with this qualification. Students may choose to switch between the BSc (Hons) and MPhys (Hons) programs up to fourth year, plus at the time of this study there was an elevated hurdle at the start of fourth year for continuation on the MPhys (Hons) program. Therefore, numbers graduating with each qualification are not necessarily the same as on entry. It is not known how many female students in this dataset entered the university intending on completing a BSc (Hons) program, however a previous study suggested that men are more likely than women to remain on integrated master's degrees from entry to graduation [11]. $41 \%$ of male and $38 \%$ of female students graduated with a MPhys (Hons). This is in agreement with the UK national picture, which shows that on average across UK HE institutions, $41 \%$ of men and $37 \%$ of women exit with a MPhys (Hons) degree [11].

Degree classifications for students who attained a BSc (Hons) or MPhys (Hons), disaggregated by gender are shown in Fig. 2. 87\% of male and 93\% of female students who graduated with a MPhys (Hons) attained a first class or second class (upper) classification, compared to $55 \%$ of male and $78 \%$ of female students who graduated with a BSc (Hons). $\chi^{2}$ tests performed on both the BSc (Hons) and MPhys (Hons) qualification, showed a statistically significant association between gender and classification for the
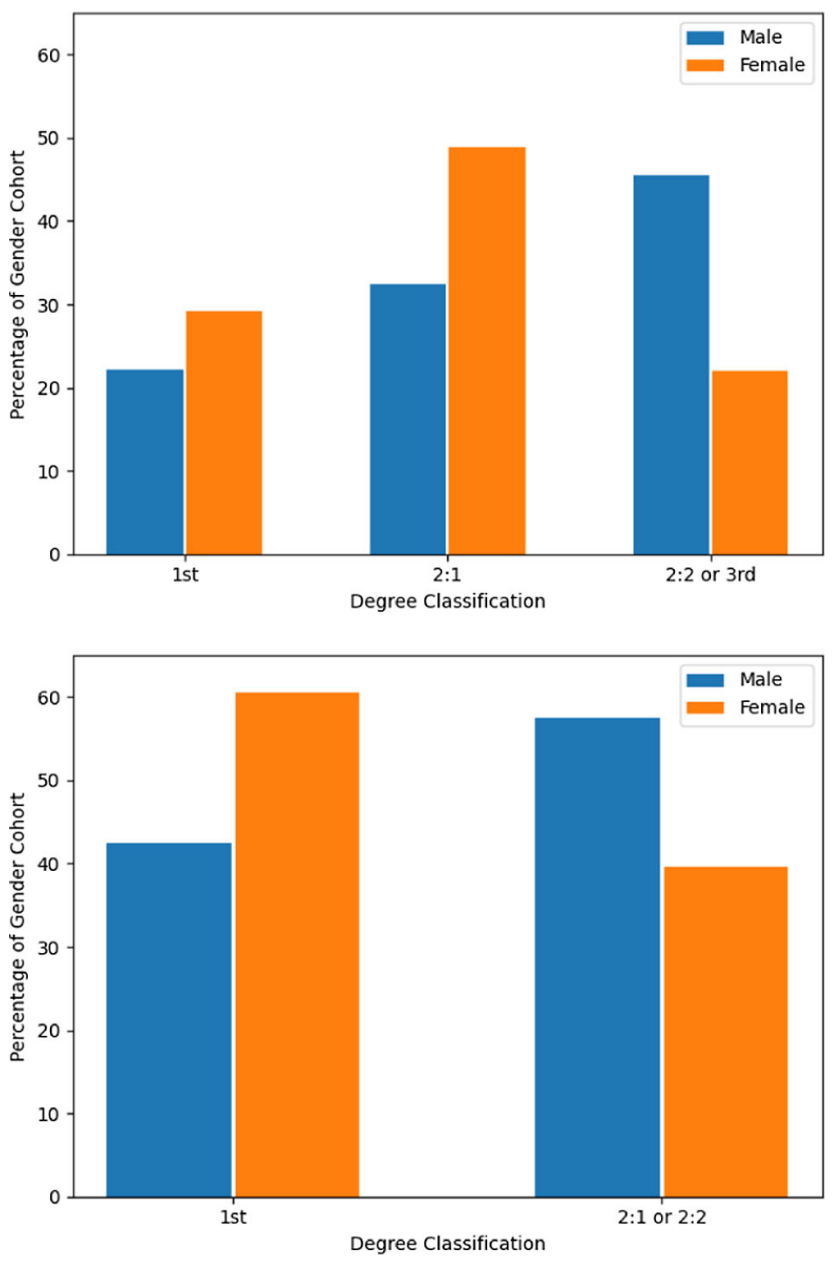

FIG. 2. Proportional split of classifications achieved by students who exited with (a) a BSc (Hons) $(N=140$, Male $=99$, Female $=41)$, (b) an MPhys (Hons) $(N=177$, Male $=134$, Female $=43$ ).

MPhys (Hons) $\left(\chi^{2}=4.20, \mathrm{df}=1, \quad p=0.04\right)$. Given that $6 \mathrm{pp}$ more female than male students exited with a BSc (Hons) (Fig. 1), and that for both BSc (Hons) and MPhys (Hons) qualifications female students attained higher classifications than male students, this suggests that some female students may have chosen to graduate with a BSc (Hons) for reasons other than academic potential.

\section{Year-on-year performance}

The yearly average marks of female and male students in both the first year entry and direct entry cohorts are shown in Fig. 3. Female students outperformed male students in their first year of study in both the first year and direct entry cohorts. Looking at the first year entry cohort, the yearly average mark for females declined by $4 \mathrm{pp}$ between year 1 and year 2, dropping below the average for males which declined by only $0.3 \mathrm{pp}$. Paired $t$ tests found the decrease in academic performance between first and second year for the female cohort to be statistically significant $[t(35)=3.75, p<0.001]$. 

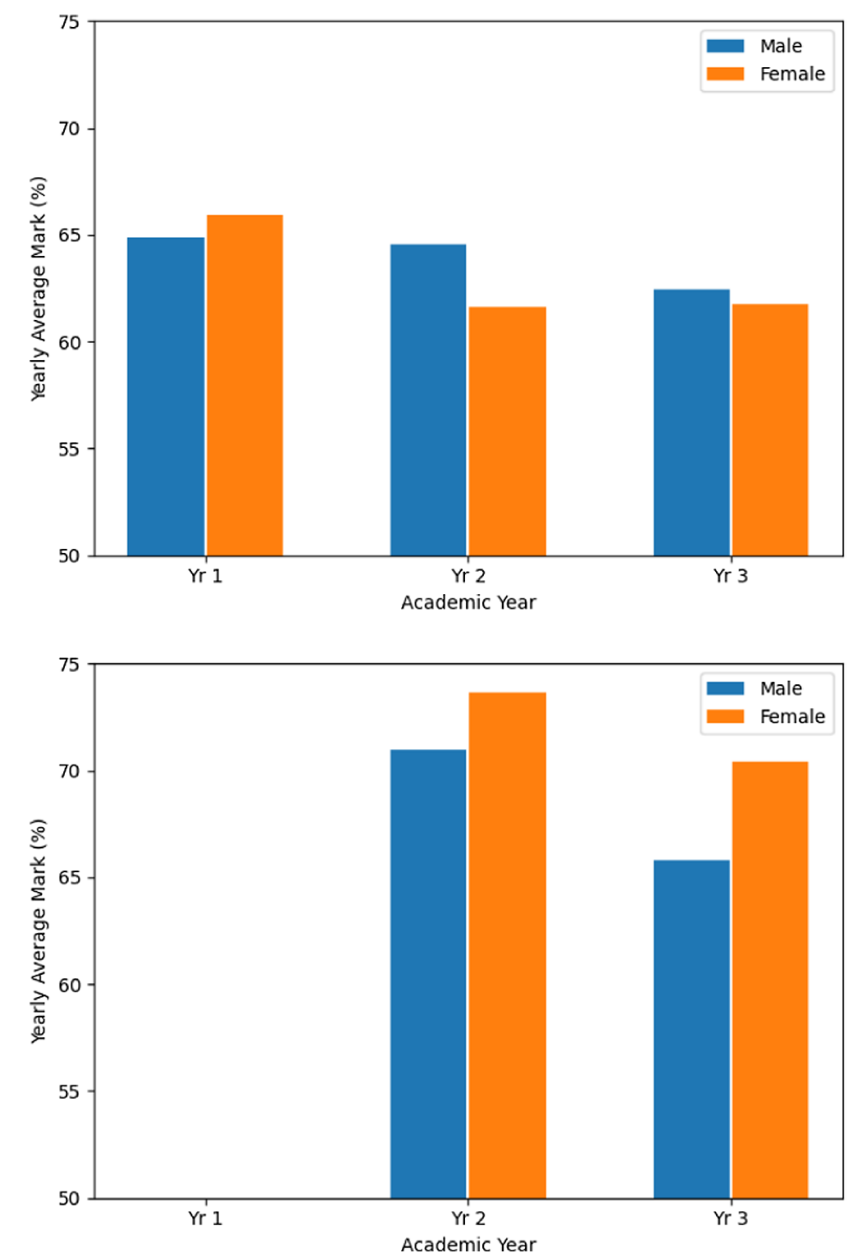

FIG. 3. Yearly average marks of male and female students per academic year for (a) first year entry cohort $(N=105$, Male $=69$, Female $=36)$, (b) direct entry cohort $(N=26$, Male $=18$, Female $=8$ ). Note that there are no Yr 1 marks because this cohort enters directly into Yr 2.

Yearly average marks similarly declined for the direct entry cohort between students' first and second year of study (academic years 2 and 3). In contrast to the first year entry cohort there is a more marked decline for male students, with female students remaining at a slightly higher average. The average yearly mark for female students declined by $3 \mathrm{pp}$, and for male students by 5 pp. Paired $t$ tests conducted separately for males and females, found both of these declines to be statistically significant $[$ females: $t(8)=3.08, \quad p=0.02$, males: $t(18)=2.67, p=0.02]$.

For the first year entry cohort, the yearly average marks of female students recovers slightly between years 2 and 3 , though is still below the average of male students, which itself declines between years 2 and 3 . The continued decline of academic performance of male students seen in both first year and direct entry cohorts as academic study progresses, could explain why a lower proportion of male students (compared to female students) went on to exit with a first or second class (upper) classification.

Given that the average yearly mark for female students in the first year entry cohort is lower than male students, it is interesting then that a higher proportion of female students than male went on to attain a first class of second class (upper) qualification, and that from a.1 a significant association between gender and exit classification [for MPhys (Hons)] was found. This would suggest there was an increase in their academic performance in fourth and fifth year. Further work would be needed to confirm this. However, it would be necessary to use a different approach to that taken in this study. We have compared results for compulsory courses taken by the whole cohort, but this approach cannot be used for fourth and fifth year as the flexibility of the degree structure in these years means that students have a wide choice of options but take very few compulsory courses.

It may be that efforts were made by the institution to combat the negative effects of underrepresentation, and over time they had a positive impact. Alternatively, it may be that by their later years of study, self-aware female students themselves combated these effects. It has been shown that, for underrepresented groups, a strong connection to one's future self increases motivation and academic achievement by directing attention away from the present and towards the future [47,48]. It is likely that this connection grows in the final years of study, as students tailor their degrees to their individual interests and more discussion ensues around career aspirations. We did not investigate the classroom experience of the students whose performance we analyse here, so we cannot make a direct comparison between classroom experience and performance for these student cohorts. However, there is evidence in the wider literature that peer interaction and recognition by instructors or teaching assistants can moderate womens' classroom experiences [28]. For the cohorts of students considered here, these situations are more likely to have occurred in later years of study, where class sizes are significantly smaller and students have built relationships with instructors, so these literature results on classroom experience may help explain our performance results.

Two sample $t$ tests, conducted separately for the first year entry and direct entry cohorts, and for each academic year (years 1-3 for first year entry, years 2-3 for direct entry) found no statistically significant gender performance gaps in yearly average marks. This is consistent with a previous study, which found no significant gender gaps in end of course examinations for first year physics students at the University of Edinburgh [14].

\section{Performance in mathematics vs physics courses}

First and second year average marks for first year entry male and female students, disaggregated by type of course, are shown in Fig. 4. For both male and female students, 


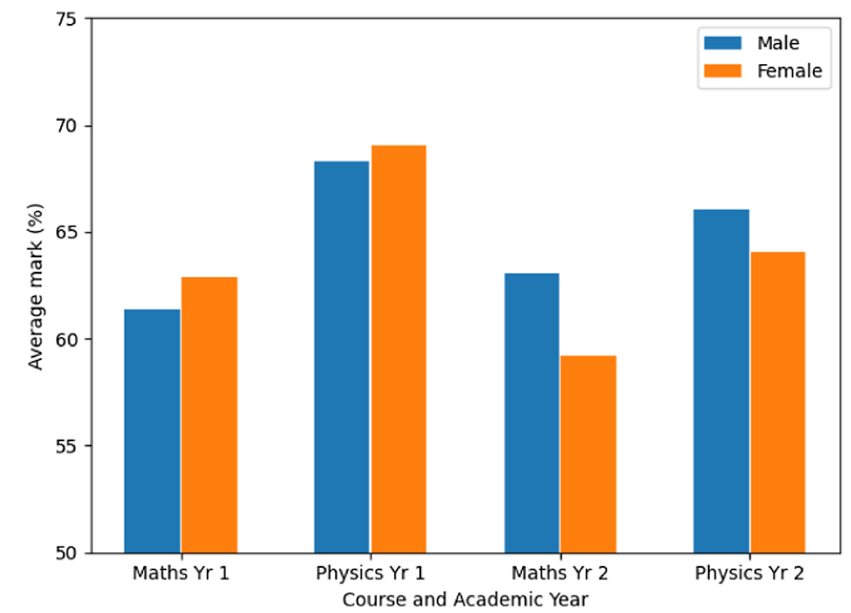

FIG. 4. Academic performance of male and female first year entry students in first and second academic year mathematics and physics courses $(N=105$, Male $=69$, Female $=36)$.

academic performance in physics is higher than in mathematics. Between first and second year, female averages declined for both course types, whereas male averages increased for mathematics and decreased for physics.

Paired $t$ tests showed the decline in academic performance of female students between first and second year to be significant across both course types [mathematics: $t(35)=2.57, p=0.01$, physics: $t(36)=3.08, p=0.004]$. For male students, only the decline between first and second year physics courses was statistically significant $[t(68)=2.33, p=0.002]$. Two sample $t$ tests did not show any significant gender difference across course type or academic year. From these results, it appears that the decline of male academic performance in the initial years of their physics degree can be attributed more specifically to a decline of performance in their physics courses (as opposed to mathematics).

Many studies have shown that both male and female physics students' level of expertlike thinking declines after initial (first year) instruction (see, for example, Ref. [49]). It has been suggested this decrease in expertlike thinking could be linked to a drop in confidence, related to a stage of intellectual development [50]. It could be that this stage of development continues into students' second year of study. There is also evidence that male and female high school students both perceive mathematics as a more masculine subject than physics [51], but that this perception only adversely affects female students' academic performance [52]. This perception is likely carried into higher education, which may explain the additional decline of female students' mathematics averages compared to male students.

\section{Overall gender discussion}

Underrepresentation, for female students who entered the school between 2012-2013 and 2014-2015, did not result in a quantifiable and statistically significant adverse effect on their educational outcome, in either the exit qualification or the classification they attained. Similarly, there was no significant performance gap between female and male students' yearly average marks in any academic year considered in this study. The reasons why a higher proportion of these female students exited with a BSc (Hons), despite higher classification attainment, should be investigated further.

Male students experienced a steady decline of academic performance throughout the first three years of their degree, although these declines were not statistically significant. A lower proportion of male students than female exited with a first class or second class (upper) classification. This should be explored further, as the reasons for this are not well understood. Both male and female students experienced an early decline in academic performance in physics-based courses. This is line with the findings of previous studies at the University of Edinburgh, and may be due in part to a stage of intellectual development.

Students experienced a decline in academic performance between their first and second year of study irrespective of gender or whether they were first year or direct entry students. For the direct entry cohort, this decline was deemed statistically significant for both males and females. For the first year entry cohort, the decline was only deemed significant for female students.

\section{B. Widening participation}

The proportion of students who entered the School of Physics and Astronomy in 2012-13, 2013-14, and 201415 that were classified as WP students is given in Table IV. For the aggregated dataset, $25 \%$ were WP students. Over the entry sessions considered, the gender ratio of the WP cohort became more representative of the overall cohort. In 2012-13, 93\% of the WP cohort was male, compared to $85 \%$ of the overall cohort. By $2014-15,66 \%$ of the WP cohort and $69 \%$ of the overall cohort was male.

\section{Exit qualification and classification}

For the aggregated dataset, the percentage of WP and non-WP students that attained each type of exit qualification is shown in Fig. 5. A $\chi^{2}$ test found no statistically significant association between WP status and exit qualification. Nevertheless, some differences can be observed from inspection of the figure. Between no qualification and the MPhys (Hons) qualification, there is an almost monotonic increase in the proportion of non-WP students that attained each type. In contrast, fewer WP students attained a MPhys (Hons) than a BSc (Hons), and 12 pp fewer WP students exited with a MPhys (Hons) qualification than non-WP students.

9\% of the non-WP cohort and $13 \%$ of the WP cohort either achieved no qualification or transferred to a degree program in another school. These percentages should not be interpreted as dropout rates, as transfers between degree 


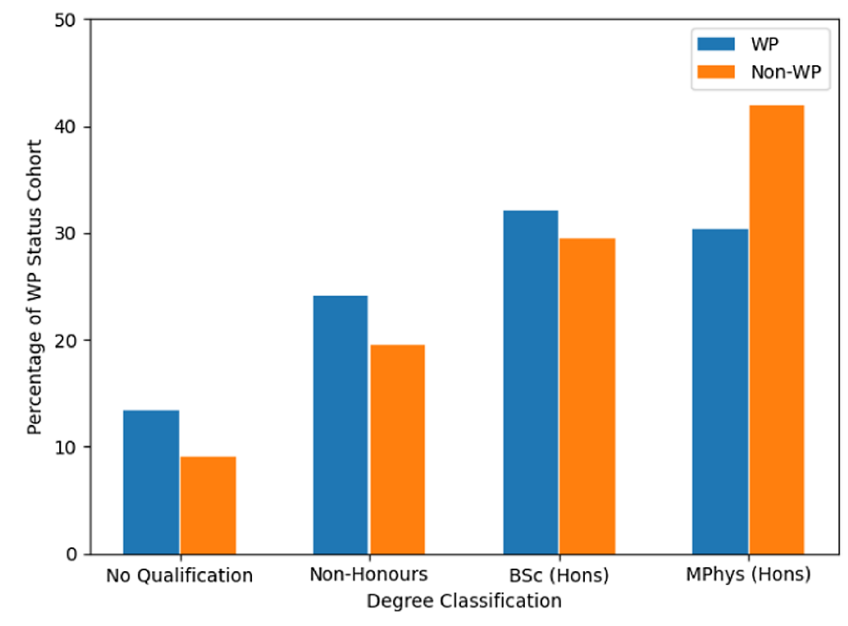

FIG. 5. Percentage of cohort exiting with each qualification type, disaggregated by WP status $(N=322$, WP $=112$, non$\mathrm{WP}=210)$. CertHE, DipHE, and BSc (Ord) have been grouped as Non-honor's due to low numbers.

programs are not uncommon, particularly in the early years. Nevertheless, the higher percentage for the WP cohort is consistent with previous research that has shown there are steep socioeconomic gradients in dropout at UK institutions, even within the same degree program [9].

Degree classifications attained by students who exited with a BSc (Hons) or a MPhys (Hons), disaggregated by WP status, are shown in Fig. 6. 77\% of non-WP students who exited with a BSc (Hons) or MPhys (Hons) achieved a first class or second class (upper) qualification, compared to $67 \%$ of WP students. A $\chi^{2}$ test did not find any statistically significant association between WP status and classification, possibly due to the relatively low number of WP students in the dataset.

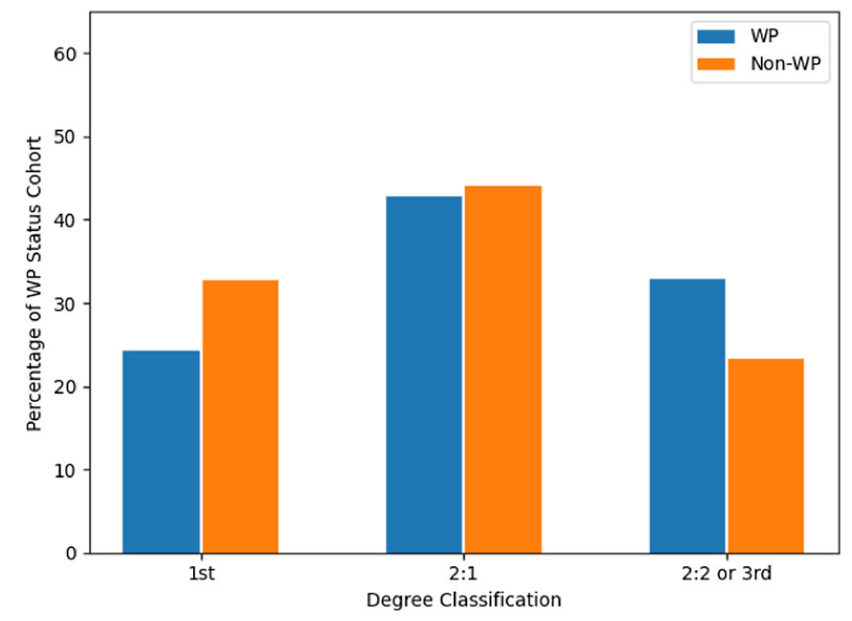

FIG. 6. Proportional split of classifications achieved by students who exited with a BSc (Hons) or MPhys (Hons), disaggregated by WP status $(N=220, \mathrm{WP}=70$, non-WP $=150)$.

\section{Year-on-year performance}

Overall average marks for first year entry and direct entry students, dissagregated by WP status, are shown in Fig. 7. It can be seen that non-WP students outperformed WP students in every academic year and for both first year entry and direct entry cohorts. All groups experienced a decline in their academic performance as they progressed, however WP students' performance declined to a greater degree. Two sample $t$ tests found that the difference between the year 2 averages of first year entry WP and nonWP students was statistically significant $[t(111)=2.06$, $p=0.04]$. This early performance gap could be one reason why more WP students exited with no qualification or a nonhonor's qualification (Fig. 5).

Paired $t$ tests showed that, on average, first year entry students, irrespective of WP status, experienced a significant decline in their academic performance between second and third year. This is consistent with the findings of the
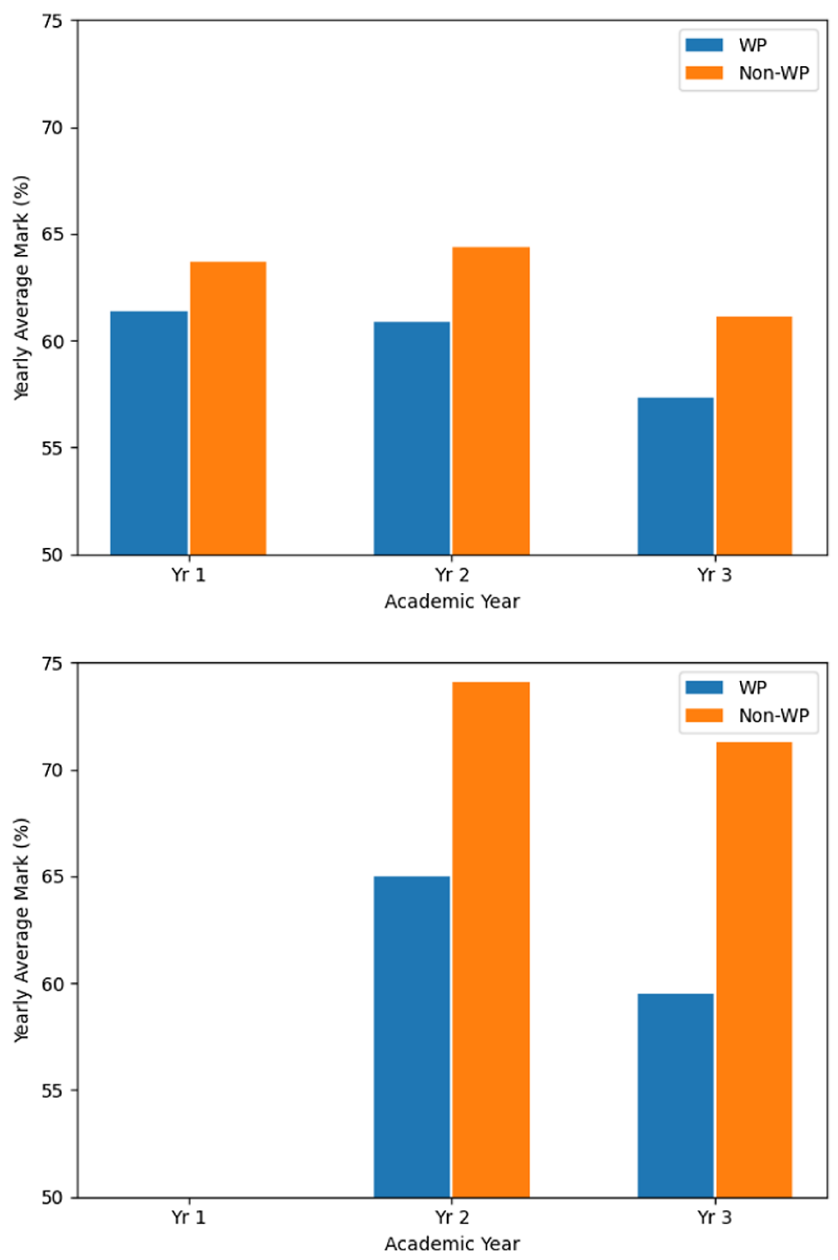

FIG. 7. Yearly average marks of WP and non-WP students per academic year for (a) first year entry cohort $(N=113, \mathrm{WP}=43$, non-WP $=70)$, (b) direct entry cohort $(N=19$, WP $=6$, non$\mathrm{WP}=13)$. Note that there are no Yr 1 marks because this cohort enters directly into Yr 2. 
previous section, where no association was found between WP status and classification. It may also suggest that for students who completed years 3, 4, and 5 (where applicable), WP status did not significantly affect academic performance.

It is interesting then that $12 \mathrm{pp}$ fewer WP students completed the MPhys (Hons) qualification. It has been suggested that inequalities in access to a postgraduate degree for underrepresented groups, such as WP students, can be largely attributable to difficulties in attainment at first degree level [53]. Therefore, even though most of the differences in academic performance are not statistically significant, the slightly higher decline of WP students' academic performance, coupled with a lower MPhys (Hons) attainment rate, may suggest they were potentially adversely affected by the consequences of underrepresentation.

No significant differences were found for the direct entry cohort, either between WP and non-WP performance, or in the differences in performance within both groups between second and third year. These results suggest that underrepresentation did not result in a significant adverse effect on academic performance for WP direct entry students, however a larger dataset would be needed to confirm this. Nevertheless, these findings are in agreement with those from previous studies that found, when comparing students with the same pre-university grades, students from the lowest performing schools perform as well or better than students from the highest performing schools $[9,31,33]$. In our study, the higher academic entry requirements required for direct entry could be considered as a proxy control for pre-university grades.

\section{Performance in mathematics vs physics courses}

The first and second year academic performance of first year entry WP and non-WP students, disaggregated by type

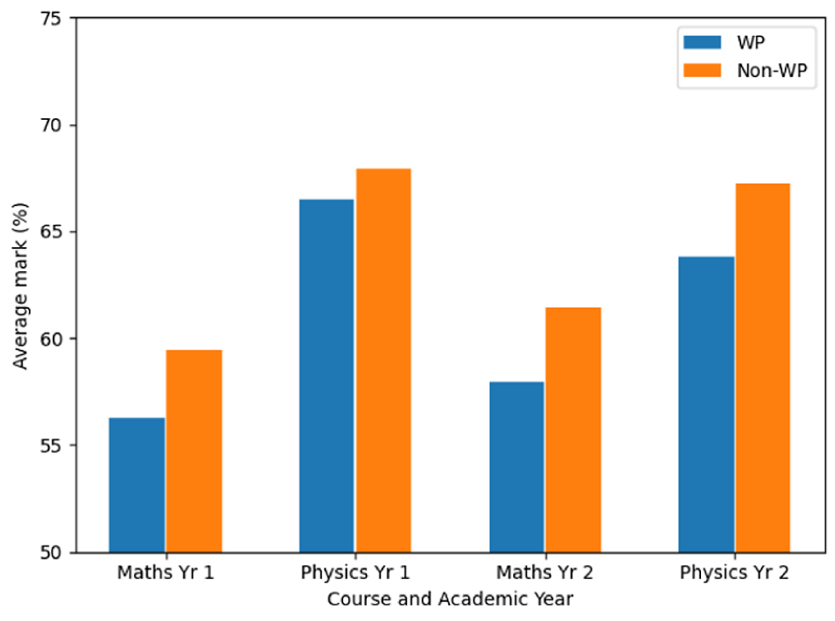

FIG. 8. Academic performance of WP and non-WP first year entry students in first and second academic year mathematics and physics courses $(N=113, \mathrm{WP}=43$, non-WP $=70)$. of course, are shown in Fig. 8. For all students, performance in mathematics was weaker than in physics, although slight improvements are observed between first and second year. The performance in physics declined in second year for both WP and non-WP students, although to a greater degree for WP students. Paired $t$ tests showed that the change in academic performance between first year and second year maths or physics courses was not significant for either WP or non-WP students. This is consistent with the overall steady decline of academic performance seen in Fig. 7 for both groups. The largest performance gap between WP and non-WP students is observed in second year mathematics, with a difference of $4.2 \mathrm{pp}$. This difference was determined to be significant $[t(111)=2.19, p=0.03]$, and is the source of the overall significant difference in year 2 performance between WP and non-WP students found in the previous section.

\section{Overall widening participation discussion}

For the cohort of WP students who entered the school between 2012-13 and 2014-15, underrepresentation was not manifested in a statistically significant adverse effect on attainment, either in the type of exit qualification or in degree classification. However, the fact that a smaller proportion of WP students graduated with a first or second class (upper) MPhys (Hons) degree may have had an impact on the opportunities open to this group for postgraduate study. Both WP and non-WP students experienced a decline in academic performance between academic years 1 to 3 , with WP students' average marks consistently lower than those of their non-WP peers, and declining at a slightly higher rate year-on-year. For direct entry students, no significant difference was found between WP and nonWP performance, possibly due to the higher entry requirements for direct entry; equivalent pre-university grades are known to close the WP performance gap. For first-year entry students, a significant performance gap was identified in second year, which can be attributed more specifically to a significant mathematics performance gap. This may be because WP students are more likely to be less wellprepared mathematically than their non-WP counterparts (as the entry requirements for WP are lower than the standard requirements). There is evidence that physics students who are less well prepared mathematically on entry may lose confidence in their mathematics ability over the course of their first year, and that this can carry forward and impact their performance in second year [54].

This early performance gap may explain why, despite not being statistically significant, a higher proportion of WP students exited with no qualification or a non-honor's qualification.

\section{Intersectionality}

$\chi^{2}$ tests conducted separately for those who attained an honor's qualification [BSc (Hons) and MPhys (Hons)], a 
non-honor's qualification [CertHE, DipHE and BSc (Ord)], and a non-honor's qualification grouped with no qualification, all returned nonsignificant results.

This suggests that, for each qualification type, there is no significant association between gender and WP status. This is perhaps surprising, given that some previous studies have highlighted that WP male students, as one of the underrepresented groups in UK higher education, are particularly susceptible to noncontinuation $[55,56]$. Intersectionality studies are crucial to gain a better understanding of how various characteristics contribute to an individual's experience in higher education physics. Very few studies to date have considered these intersections and this would therefore provide a salient focus for future research.

\section{Data quality and future studies}

It has been suggested [26] that the consequences of effects such as stereotype threat may have a particularly negative impact on higher ability students. This was not seen in this study, either for gender or WP status (where direct entry was taken as a proxy for higher ability). However, our analysis was limited by the relatively small size of the direct entry cohort so further work to investigate this would be worthwhile.

In order to make fair and consistent comparisons in yearon-year performance (a.2 and b.2), a complete case analysis approach was taken, which inevitably led to the removal of several students from the dataset. When the students were omitted from the sample their gender, WP status and reason for removal was noted. The most common reasons for removal were switching degree program (within the School), taking a year out, undertaking a year abroad or resitting a year. The students removed did not disproportionally come from any one WP status or gender, but whether the reasons for removal are significantly associated with those groups, and therefore the effects of underrepresentation, are not known. In future work, the missing completely at random (MCAR) assumption should be explicitly tested, as it is acknowledged that these removals can lower the statistical power of the analysis and may bias the results [57].

A Bayesian approach to this type of study may also be a promising avenue forward [58]; we are currently undertaking corresponding work utilizing this approach.

The scope of our study is, of course, limited. There are many underrepresented groups in higher education in addition to WP students and (in physics and some other disciplines) female students; for example, Black, Asian, and minority ethnic students, and disabled students. Further work is needed to study the impact of underrepresention on the academic performance of these groups.

Finally, academic performance is not a sole indicator, either of a student's educational experience, or of the effects of underrepresentation. Therefore, in order to understand how underrepresentation permeates all aspects of a student's higher education journey, qualitative data in the form of interviews or focus groups should be collected, to enhance the insight that can be gained from such a study.

\section{CONCLUSION}

The academic performance of undergraduate cohorts of students who entered the School of Physics and Astronomy at the University of Edinburgh in 2012-13, 2013-14, and 2014-15 have been analyzed with the aim of identifying any significant gaps between the performance of male and female, and WP and non-WP students. No significant associations were found between gender and type of exit qualification. However, gender was found to be significantly associated with the classification that MPhys (Hons) students attained, with a higher proportion of female students exiting with a first class or second class (upper) classification than male students. This cohort of female students were perhaps resilient to, or were able to mitigate, the adverse effects of underrepresentation. In contrast, a higher proportion of female students exited with a BSc (Hons) compared to male students, suggesting that some female students may choose to exit with a BSc (Hons) for reasons other than academic performance. There were no significant year-on-year gender performance gaps, however for both male and female students their performance in physics courses significantly declined between first and second year. This supports previous research at the University of Edinburgh, which found that physics students' level of expert like thinking declines after a period of initial instruction, possibly due to a drop in confidence linked to a stage of intellectual development $[49,50]$. It is also worth noting that, because the students in our study had a range of educational backgrounds, the material in first year was more familiar to some students than to others. This familiarity may have resulted in both a higher overall performance and a higher level of confidence in first year than in subsequent years.

Exit qualification and classification were not significantly associated with WP status. This suggests that, overall, WP students were able to perform academically at a similar level to their peers. However, WP students' performance was consistently lower than that of non-WP students year-on-year; and a higher proportion of WP students exited with either no qualification or a non-honor's qualification. The difference in academic performance between WP and non-WP students was statistically significant in second year; this appears to be due to a significant difference in their performance in mathematics courses. For students who entered directly into the second academic year of study, no significant performance gaps were found for either female or WP students. This is in contrast to previous studies that found the effects of 
underrepresentation to have more impact on students of a higher ability.

These findings - no performance gap for direct entry students, and relatively little performance gap for first year entry students-do not align completely with the UK national picture or with previous research. This suggests that the widely established effects of underrepresentation may not generalize fully to specific populations at specific institutions. For example, perhaps the student cohorts in our study, in gaining entry to a physics degree at a highly selective university, had already developed some level of resilience against the effects of underrepresentation. Taking account of entry qualifications, comparing students of the same underrepresented groups in both first year entry and direct entry settings, and collecting qualitative data to complement quantitative findings, would both deepen understanding and help to define the boundaries of such phenomena.

A key implication of our findings is that in these types of studies it is important to take account of the context of the population that the sample is drawn from. Otherwise, the evidence (nationally averaged) underpinning their policies (locally implemented) might be inappropriate; in other words, an intervention that is effective at one institution, or one type of institution, might not be effective at another. This is especially relevant for higher education systems such as that in the UK where different institutions have different entry level requirements. Broadly speaking, no single university is the same as the "nationally averaged university," so using national data to underpin policy at any one university may not be appropriate.
Our findings also have an important policy implication: It is crucial that individual institutions collect and report appropriate data about the academic performance and experience of their students, particularly their marginalized students, so that institutions can implement evidence-based interventions to support their students to succeed. More locally relevant data, both quantitative and qualitative, should help direct often limited resources to "pinch points" in the local system where they are most likely be effective in improving the experience of students in that local system.

\section{ACKNOWLEDGMENTS}

J. H. J. T. acknowledges EPSRC EP/S012087/1 . We thank Katie Nicoll Baines, Emily Porth, and Ozioma Kamalu for useful discussions during the early stages of the project design.

\section{APPENDIX: COMPULSORY COURSES FOR THE PHYSICS DEGREE IN ACADEMIC YEARS 1-3}

Table V lists the compulsory courses of the standard physics degree at the University of Edinburgh (UK) for academic years 1-3 for first-year entry for the cohorts considered; Table VI lists the compulsory courses of the standard physics degree at the University of Edinburgh (UK) for academic years 1-3 for second-year (direct) entry for the cohorts considered.

TABLE V. Compulsory courses: First year entry.

\begin{tabular}{lcc}
\hline \hline Year 1 & Year 2 & ${\text { Year } 3^{\mathrm{a}}}^{\mathrm{a}}$ \\
\hline Physics 1A (S1) & Modern physics (S1) & Fourier analysis and statistics (S1) \\
Maths for physics 1 (S1) & Linear algebra and several variable calculus (S1) & Thermal physics (FY) \\
Physics 1B (S2) & Dynamics and vector calculus (S2) & Electromagnetism (FY) \\
Maths for physics 2 (S2) & Physics of fields and matter (S2) & Quantum mechanics (FY) \\
\hline \hline
\end{tabular}

${ }^{\mathrm{a}} \mathrm{S} 1$ : Semester 1 Course, S2: Semester 2 Course, FY: Full Year Course.

TABLE VI. Compulsory courses: Direct (second year) entry.

\begin{tabular}{lc}
\hline \hline Year 2 & ${\text { Year } 3^{\mathrm{a}}}^{\mathrm{a}}$ \\
\hline Classical and modern physics (S1) & Fourier analysis and statistics (S1) \\
Algebra and calculus (S1) & Thermal physics (FY) \\
Dynamics and vector calculus (S2) & Electromagnetism (FY) \\
Physics of fields and matter (S2) & Quantum mechanics (FY) \\
\hline \hline
\end{tabular}

${ }^{\mathrm{a}} \mathrm{S} 1$ : Semester 1 Course, S2: Semester 2 Course, FY: Full Year Course. 
[1] B. Ertl, S. Luttenberger, and M. Paechter, The impact of gender stereotypes on the self-concept of female students in STEM subjects with an under-representation of females, Front. Psychol. 8, 703 (2017).

[2] E. J. Theobald et al., Active learning narrows achievement gaps for underrepresented students in undergraduate science, technology, engineering, and math, Proc. Natl. Acad. Sci. U.S.A. 117, 6476 (2020).

[3] National Academy of Sciences, National Academy of Engineering, and Institute of Medicine, Expanding Underrepresented Minority Participation: America's Science and Technology Talent at the Crossroads (The National Academies Press, Washington, DC, 2011), 10.17226/ 12984

[4] National Academies of Sciences, Engineering, and Medicine, Barriers and Opportunities for 2-Year and 4-Year STEM Degrees: Systemic Change to Support Students' Diverse Pathways, edited by S. Malcom and M. Feder (The National Academies Press, Washington, DC, 2016), $10.17226 / 21739$.

[5] National Center for Science and Engineering Statistics, Women, Minorities, and Persons with Disabilities in Science and Engineering: 2021, Special Report NSF 21321 (National Science Foundation, Alexandria, VA, 2021), https://ncses.nsf.gov/wmpd.

[6] European Commission, She Figures 2018, Tech. Rep. (European Commission, Brussels, 2019).

[7] Z. Y. Kalender, E. Marshman, C. D. Schunn, T. J. NokesMalach, and C. Singh, Why female science, technology, engineering, and mathematics majors do not identify with physics: They do not think others see them that way, Phys. Rev. Phys. Educ. Res. 15, 020148 (2019).

[8] P. R. Clance and S. A. Imes, The imposter phenomenon in high achieving women: Dynamics and therapeutic intervention, Psychol. Psychother. 15, 241 (1978).

[9] C. Crawford, Socio-economic differences in university outcomes in the UK: drop-out, degree completion and degree class, IFS Working Paper W14/31 (2014).

[10] V. P. Coletta, J. A. Phillips, and J. Steinert, FCI normalized gain, scientific reasoning ability, thinking in physics, and gender effects, AIP Conf. Proc. 1413, 23 (2012).

[11] S. McWhinnie, Physics Students in UK Higher Education Institutions (Statistical Report), Tech. Rep. (Institute of Physics, New York, 2012).

[12] David Hestenes, Malcolm Wells, and Gregg Swackhamer, Force Concept Inventory, Phys. Teach. 30, 141 (1992).

[13] J. Docktor and K. Heller, Gender differences in both force concept inventory and introductory physics performance, AIP Conf. Proc. 1064, 15 (2008).

[14] S. Bates, R. Donnelly, C. MacPhee, D. Sands, M. Birch, and N. R. Walet, Gender differences in conceptual understanding of Newtonian mechanics: A UK cross-institution comparison, Eur. J. Phys. 34, 421 (2013).

[15] A. Traxler, R. Henderson, J. Stewart, G. Stewart, A. Papak, and R. Lindell, Gender fairness within the Force Concept Inventory, Phys. Rev. Phys. Educ. Res. 14, 010103 (2018).

[16] A. Madsen, S. B. McKagan, and E. C. Sayre, Gender gap on concept inventories in physics: What is consistent, what is inconsistent, and what factors influence the gap?, Phys. Rev. ST Phys. Educ. Res. 9, 020121 (2013).

[17] UK National Committee of Inquiry into Higher Education (The Dearing Committee), Higher Education in the Learning Society: Report of the National Committee, London: HMSO (1997).

[18] Higher Education Statistics Agency, HE student enrollments by subject of study 2014-15 to 2018-19 (2020).

[19] Higher Education Statistics Agency, Students in Higher Education Institutions 1994-95 (1996).

[20] Eurostat, Students enrolled in tertiary education by education level, programme orientation, sex and field of education (2021).

[21] Institute of Physics, Degree accreditation and recognition (2021).

[22] C. Crawford and E. Greaves, Socio-economic, ethnic and gender differences in HE participation (Research Paper No.186), Tech. Rep. (Department for Business, Innovation \& Skills, London, 2015).

[23] In part, the lack of an agreed UK definition of widening participation is because socioeconomic background is not a protected characteristic under the UK Equality Act 2010 [24].

[24] HM Government, Equality Act 2010 (2010), https://www .legislation.gov.uk/ukpga/2010/15/contents.

[25] Institute of Physics, We are physicists: Results of the IOP member diversity survey 2019, Tech. Rep. (Institute of Physics, New York, 2020).

[26] J. Robertson, A. Williams, D. Jones, L. Isbel, and D. Loads, EqualBITE: Gender Equality in Higher Education (Sense Publishers, Netherlands, 2018).

[27] H. M. Hutchins and H. Rainbolt, What triggers imposter phenomenon among academic faculty? A critical incident study exploring antecedents, coping, and development opportunities, Hum. Resour. Dev. Int. 20, 194 (2017).

[28] Z. Y. Kalender, E. Marshman, C. D. Schunn, T. J. NokesMalach, and C. Singh, Gendered patterns in the construction of physics identity from motivational factors, Phys. Rev. Phys. Educ. Res. 15, 020119 (2019).

[29] S. D. Herrmann, R. M. Adelman, J. E. Bodford, O. Graudejus, M. A. Okun, and V.S. Y. Kwan, The effects of a female role model on academic performance and persistence of women in STEM courses, Basic Appl. Soc. Psychol. 38, 258 (2016).

[30] R. M. Lock and Z. Hazari, Discussing underrepresentation as a means to facilitating female students' physics identity development, Phys. Rev. Phys. Educ. Res. 12, 020101 (2016).

[31] J. Smith and R. Naylor, Determinants of degree performance in UK universities: A statistical analysis of the 1993 student cohort, Oxford. B. Econ. Stat. 63, 29 (2008).

[32] G. Johnes and R. McNabb, Never give up on the good times: Student attrition in the UK, Oxford. B. Econ. Stat. 66, 23 (2004).

[33] A. F. Vignoles and N. Powdthavee, The socioeconomic gap in university dropouts, Brit. Econ. J. 9, 19 (2009).

[34] M. Mears, Gender differences in the force concept inventory for different educational levels in the United Kingdom, Phys. Rev. Phys. Educ. Res. 15, 020135 (2019). 
[35] R. Henderson, J. Stewart, and A. Traxler, Partitioning the gender gap in physics conceptual inventories: Force concept inventory, force and motion conceptual evaluation, and conceptual survey of electricity and magnetism, Phys. Rev. Phys. Educ. Res. 15, 010131 (2019).

[36] A. L. Traxler, X. C. Cid, J. Blue, and R. Barthelemy, Enriching gender in physics education research: A binary past and a complex future, Phys. Rev. Phys. Educ. Res. 12, 020114 (2016).

[37] S. Kanim and X. C. Cid, Demographics of physics education research, Phys. Rev. Phys. Educ. Res. 16, 020106 (2020).

[38] Definitions are given to avoid ambiguity in interpreting these terms in the context of this paper rather than to suggest they are the true or only definition; there are many accepted interpretations of these terms.

[39] While the term widening participation is used throughout the UK, distinct approaches have developed across the UK administrations when addressing participation inequalities since the devolution of education policy in 1998 [40].

[40] M. Donnelly and C. Evans, A 'home-international' comparative analysis of widening participation in UK higher education, High. Educ. 77, 97 (2019).

[41] L. Croxford, G. Docherty, R. Gaukroger, and K. Hood, Widening Participation at the University of Edinburgh: Contextual Admissions, Retention and Degree Outcomes, Scottish. Aff. 23, 192 (2014), https:/www.euppublishing .com/doi/full/10.3366/scot.2014.0017.

[42] The lack of gender options available to students during data collection is acknowledged as a limitation of this study.

[43] A. K. Wood, R. K. Galloway, C. Sinclair, and J. Hardy, Teacher-student discourse in active learning lectures: Case studies from undergraduate physics, Teach. High. Educ. 23, 818 (2018).

[44] University of Edinburgh Degree Regulations and Programmes of Study, Degree Programme Tables 2020/21 (2020).

[45] University of Edinburgh DataShare (2021), 10.7488/ds/ 3398.

[46] J. Schmuller, Statistical Analysis with Excel for Dummies (John Wiley \& Sons Inc., New York, 2013).
[47] D. Oyserman, Identity-based motivation: Implications for action-readiness, procedural-readiness, and consumer behavior, J. Consum. Psychol. 19, 250 (2009).

[48] R. M. Adelman, S. D. Herrmann, J. E. Bodford, J. E. Barbour, O. Graudejus, M. A. Okun, and V. S. Y. Kwan, Feeling closer to the future self and doing better: Temporal psychological mechanisms underlying academic performance, J. Pers. 85, 398 (2017).

[49] K. A. Slaughter, S. P. Bates, and R. K. Galloway, The changes in attitudes and beliefs of first year physics undergraduates: A study using the CLASS survey, Int. J. Innov. Sci. Math. 19, 29 (2011), https://openjournals .library.sydney.edu.au/index.php/CAL/article/view/4780.

[50] W. G. Perry, Forms of Intellectual and Ethical Development in the College Years: A Scheme (Holt, Rinehart, and Winston, New York, 1970).

[51] E. Makarova, B. Aeschlimann, and W. Herzog, The gender gap in STEM fields: The impact of the gender stereotype of math and science on secondary students' career aspirations, Front. Educ. 4, 60 (2019).

[52] J. Song, B. Zuo, and L. Yan, Effects of gender stereotypes on performance in mathematics: A serial multivariable mediation model, Soc. Behav. Pers. 44, 943 (2016).

[53] P. Wakeling and C. Kyriacou, Widening Participation from Undergraduate to Postgraduate Research Degrees (Report), Tech. Rep. (Department of Educational Studies, University of York, York, 2010).

[54] R. Symonds, D. Lawson, and C. Robinson, An investigation of physics undergraduates' attitudes towards mathematics, Teach. Math. its Appl. 29, 140 (2010).

[55] S. Baars, E. Mulcahy, and E. Bernardes, The Underrepresentation of White Working Class Boys in Higher Education, Tech. Rep. (LKMco, London, 2016).

[56] N. Hillman and N. Robinson, Boys to Men: The Underachievement of Young Men in Higher Education-and How to Start Tackling It (HEPI Report 84), Tech. Rep. (Higher Education Policy Institute, Oxford, 2016).

[57] J. Nissen, R. Donatello, and B. Van Dusen, Missing data and bias in physics education research: A case for using multiple imputation, Phys. Rev. Phys. Educ. Res. 15, 020106 (2019).

[58] C. König and R. van de Schoot, Bayesian statistics in educational research: A look at the current state of affairs, Educ. Rev. 70, 486 (2018). 